\title{
Schwacher Geruchssinn, schwaches Gedächtnis
}

Schneiden ältere Personen in einem kurzen Riechtest schlecht ab, ist das Risiko für Gedächtnisprobleme verdoppelt und für eine Alzheimerdemenz verfünffacht. Das hat eine Auswertung der Mayo Clinic Study of Aging gezeigt, an der zwischen 2004 und 2010 insgesamt 1630 ältere kognitiv noch gesunde Probanden beteiligt waren, zudem noch über 300 Personen mit bereits bestehender leichter kognitiver Beeinträchtigung (MCI)[9]. Alle haben dabei einen Geruchstest absolviert: Beim „Brief Smell Identification Test“ (B-SIT) müssen die Probanden sechs Nahrungsmittel und Gewürze erriechen (Banane, Schokolade, Zimt, Ananas, Zitrone, Zwiebel) sowie sechs andere Düfte (Farbverdünner, Benzin, Seife, Rose, Rauch und Terpentin).

Die Mayo-Forscher bieten dafür mehrere Erklärungen an. So könnten sich die demenztypischen neuropathologischen Veränderungen wie etwa die Ablagerung von Amyloidplaques im olfaktorischen System früher manifestieren als im Kortex. Post-mortem-Untersuchungen an Gehirnen aus Autopsien haben gezeigt, dass etwa $12 \%$ der Variation in der Fähigkeit, Gerüche zu identifizieren, auf neuropathologische Befunde zurückgeführt werden können, die mit Morbus Alzheimer assoziiert sind.

Vielleicht teilen sich Riechstörungen und Demenz aber auch Pathomechanismen, die letztlich zu beidem führen: eine mit dem Alter abnehmende regenerative Kapazität zum Beispiel oder zunehmende immunpathologische Veränderungen. Dafür könnte sprechen, dass ältere Menschen mit Problemen beim Erkennen von Gerüchen auch unabhängig vom Bestehen einer Demenz eine erhöhte Sterblichkeit aufweisen [10].

$m u t / r b$

grenze. Das mag durchaus sein. Insgesamt nämlich besitzt die Nase schätzungsweise 350 verschiede Rezeptortypen, die je nachdem aktiv oder inaktiv sein können. Das würde zusammen 2 hoch 350 Variationen ergeben - abzüglich des einen Zustands, in welchem sämtliche Rezeptoren inaktiv sind. Das überstiege die Dimension einer 1 mit 105 Nullen um mehr als das Doppelte.

\section{Riechkolben in Luxusausgabe}

Quelle

1. Kant I. Anthropologie in pragmatischer Hinsicht (1798). Akademieausgabe $B d$. VII, S. $158 \mathrm{f}$

2. Bushdid C et al.

Science 2014; 343:

1370-2

3. Scharfenberger $G$ et al. GIT Labor-Fachzeitschrift 2013; 57(1):

19-21

4. Bublak R. MMW

Fortschr Med 2012; 154(22): 14-6

5. Kohli $P$ et al. Chem Senses 2016; 41: 479-

6. Whitcroft KL et al. Laryngoscope 2017;

127: 291-295

7. Buck L, Axel R. Cell 1991; 65: 175-87

8. Royet $\mathrm{J}$ et al. Front

Hum 2016; 10: 511

9. Roberts RO et al.

JAMA Neurol 2016; 73: 93-101

10. Devanand $D$ et al. Ann Neurol 2015; 78 .

401-11
Insgesamt besitzen Menschen 30 Millionen Riechzellen auf einer Fläche von $2 \times 5 \mathrm{~cm}^{2}$ [3]. Doch so beeindruckend all diese Zahlen sein mögen, der König der Nasen ist nicht der Mensch. Der Bulbus olfactorius des Hundes etwa ist relativ zum Gesamthirn rund 40-mal größer als der des Menschen. Auf diesem Luxusriechkolben sitzen 125 bis 220 Millionen, bei Bluthunden bis zu 300 Millionen Geruchsrezeptoren. Daraus resultiert ein Geruchssinn, der bis zu einer Million Mal sensitiver ist als der menschliche. Einige Züchtungen sollen dem Menschen sogar 100 Millionen Nasenlängen voraus sein, was die Empfindlichkeit für Gerüche angeht [4].

Undankbar, entbehrlich gar, wie Kant meinte, ist der Geruchssinn für den Menschen beileibe nicht und nicht nur deswegen, weil er vor schädlichen Substanzen warnt. Die Riechreize werden stracks zum limbischen System, einem Teil des Urhirns also, geleitet und emotional bewertet. Redensarten, wonach man die eine oder den anderen gut riechen könne oder eben nicht, orientieren sich daher nicht von ungefähr am Geruchssinn.

\section{Depression, Parkinson, Demenz}

Wie eng Seelenwohl und Geruchssinn zusammenhängen, zeigen auch Studien, die Riechstörungen mit Depressionen in Zusammenhang bringen. Demnach ist das Verhältnis offenbar reziprok. Einerseits haben Patienten mit Depressionen ein eingeschränktes Riechvermögen - und umgekehrt führt der Verlust der Riechfähigkeit zu Depressionen, und zwar je stärker, desto mehr [5]. Psychosoziale Faktoren, aber eben auch die Kommunikation zwischen olfaktorischem und limbischem System sollen hier eine Rolle spielen.

Im Gegensatz also zur Annahme des Königsberger Weltphilosophen nimmt die Wichtigkeit des Geruchssinns und seiner Physiologie nicht ab, sondern zu. Beispielsweise werden in der Diagnostik neurodegenerativer Erkrankungen Riechtests recht erfolgreich eingesetzt. Die olfaktorische Dysfunktion bei Morbus Parkinson wird auf eine Störung der zentralen Verarbeitung zurückgeführt, ohne dass die Riechschwelle als solche erhöht wäre. Die Patienten können riechen, sie wissen aber nicht was und können Gerüche nicht diskriminieren. Das unterscheidet sie etwa von Patienten, die an sinunasal bedingter Hyposmie leiden. Sie nehmen Gerüche zwar schlecht wahr, ist die Schwelle aber einmal überwunden, gelingen Diskrimination und Identifikation [6]. Inzwischen mehren sich die Hinweise, dass Störungen des Geruchssinns auch mit Demenzerkrankungen in Verbindung stehen könnten (siehe Kasten).

\section{Von Nobel zu Ig-Nobel}

Das Nobelkomitee hielt den Geruchssinn im Jahr 2004 für wichtig genug, um zwei Forschern, die seine Funktion aufgeklärt hatten, den Nobelpreis für Physiologie oder Medizin zu verleihen. Preisträger waren die US-Amerikaner Linda Buck und Richard Axel. 1991 hatten die beiden an der New Yorker Co- 